\title{
Adressen der Rezensenten
}

Prof. Dr. med., Dr. med.h. c. mult. Erwin H. Ackerknecht, Ottikerstraße 42, CH-8006 Zürich Dr. med. René Bernoulli, Amselstraße 35, CH-4.059 Basel

Prof. Dr. Marcel H. Bickel, Pharmakologisches Institut, Friedbühlstraße 49, CH-3010 Bern Dr. phil. Willem F. Daems, Weleda, CH-4144 Arlesheim

Prof. Dr. med. Carl Haffter, Petersgasse 50, CH-4051 Basel

Prof. Dr. med. Huldrych M. Koelbing, Medizinhistorisches Institut, Rämistraße 74, CH-8006 Zürich

PD Dr. med. Roger Mayer, 9, rue Michel-Chauvet, CH-1208 Genève

Prof. Dr. med. Christian Müller, Clinique Psychiatrique Universitaire-Prilly, CH-1008 Prilly Michael Quick, Otto-Richter-Straße 16f, D-8700 Würzburg

Frau Dr. med. Antoinette Stettler, Kirchenfeldstraße 45, CH-3006 Bern

Redaktionsschlüsse für die nächsten Hefte des Gesnerus:

- 27. Februar 1989 für Heft $1 / 21989$ (erscheint am 31. Mai 1989)

- 29. August 1989 für Heft 3/4 1989 (erscheint am 30. November 1989) 